\title{
Can the rate and location of sessile serrated polyps be part of colorectal Cancer disparity in African Americans?
}

\author{
Mehdi Nouraie ${ }^{1,5^{*}+}$, Hassan Ashktorab ${ }^{2,4^{*}+}$ (D) Nazli Atefi ${ }^{2}$, Saman Azam², Taraneh Tarjoman², Edward Lee ${ }^{3}$, \\ Babak Shokrani ${ }^{3}$, Ali Afsari ${ }^{3}$, Akbar Soleimani $^{2}$, Adeyinka O. Laiyemo ${ }^{2}$, Sanmeet Singh ${ }^{2}$ and Hassan Brim ${ }^{3}$
}

\begin{abstract}
Background: Up to 30\% of colorectal cancers develop through the serrated pathway. African Americans (AAs) suffer a disproportionate burden of colorectal cancer. The aim of this study was to evaluate clinicopathological features of AA patients diagnosed with sessile serrated polyps (SSPS).

Methods: We conducted a retrospective study of all colonoscopies $(n=12,085)$ performed at Howard University Hospital, from January 1st, 2010 to December 31st, 2015, of which 83\% were in AA patients, $(n=10,027)$. Among AAs, pathology reports confirmed 4070 patients with polyps including 252 with SSPs. Demographic and clinical variables (i.e. sex, age, BMl, anatomic location, clinical symptoms, polyp size, and clinical indications were collected at colonoscopy.

Results: In the AA population, the median age was 56 with interquartile range (IQR) of 51 to 62 years, 54\% were female, and $48 \%$ had a BMI > 30. The most common reason for colonoscopy was screening (53\%), whereas the prevalent reasons for diagnostic colonoscopies were changes in bowel habits (18\%) and gastrointestinal bleeding (17\%). The total number of SSPs among the 252 AA (diagnosed with SSPs) was 338. Of these, $9 \%(n=29 / 338)$ had some degree of cytological dysplasia, primarily in the ascending colon $(n=6 / 42,14 \%)$, Transverse colon $(n=2 / 16$, $13 \%)$ and rectosigmoid $(n=19 / 233,8 \%)$. About $24 \%$ of patients had more than 2 polyps. Most patients (76\%) had distal SSPs (rectal and rectosigmoid), in comparison to $14 \%$ of proximal polyps and $10 \%$ of bilateral locations. Median SSA/P size for all locations was $0.6 \mathrm{~cm}$.

Conclusion: The prevalence of SSPs accounts for $6 \%$ of all polyps in AA patients and was diagnosed in $2.5 \%$ of all colonoscopies $(n=252 / 10,027)$, which is higher than Caucasians in the US. SSPs were predominantly located in the left side, as compared to published literature showing the predominance in the right side of the colon. Screening of CRC will have the chance to detect high risk SSA/P in this population.
\end{abstract}

\section{Background}

Colorectal cancer (CRC) is the third most prevalent cancer in both sexes in the United States, and is the second leading cause of cancer-related deaths [1, 2]. A recent meta-analysis by Imperoale et al. found that there is no difference in the prevalence of advanced adenomas and advanced precancerous colorectal neoplasm between African Americans, Caucasians, and

\footnotetext{
* Correspondence: nouraies@upmc.edu; hashktorab@howard.edu

${ }^{\dagger}$ Mehdi Nouraie and Hassan Ashktorab contributed equally to this work.

${ }^{1}$ University of Pittsburg, Medical center, Pittsburg, PA, USA

2Department of Medicine, College of Medicine, Washington, DC, USA

Full list of author information is available at the end of the article
}

concluding that as such screening guidelines ought not to be changed based on patients' race [3]. Among precancerous colon polyps, serrated polyps (previously grouped with hyperplastic polyps) have been classified as non-neoplastic lesions and were not indicated for endoscopic treatment. However, during the past thirty years, there have been reports suggesting neoplastic changes in some of these lesions [4-7]. Based on the World Health Organization (WHO), serrated polyps have been classified into three groups: Hyperplastic polyps (HPs), sessile serrated polyps (SSPs), and traditional serrated adenomas (TSAs) [8]. SSPs and TSAs are known to have malignant potential [9-11]. SSPs

(c) The Author(s). 2019 Open Access This article is distributed under the terms of the Creative Commons Attribution 4.0 International License (http://creativecommons.org/licenses/by/4.0/), which permits unrestricted use, distribution, and reproduction in any medium, provided you give appropriate credit to the original author(s) and the source, provide a link to the Creative Commons license, and indicate if changes were made. The Creative Commons Public Domain Dedication waiver (http://creativecommons.org/publicdomain/zero/1.0/) applies to the data made available in this article, unless otherwise stated. 
which still remain poorly defined, generally have a flat phenotype with a mucus cap, predominant right side location, and distinctive serrated saw-toothed morphology [12-14]. SSPs were reported to be more prevalent in women [14-17]. In contrast to the well-known adenoma-carcinoma sequence, the "serrated pathway" is not well studied. It has been recognized as a novel pathway accounting for up to $30 \%$ of colon cancers $[5,9,18]$. A proportion of SSPs may develop cytological dysplasia (SSA/P-D) which may rapidly progress to carcinoma [11]. However, differentiating SSPs from HPs by colonoscopy or histopathology remains difficult due to overlapping morphological and pathological features. Li et al., recently reported a positive role of education and training in finding SSA/PS cases by gastroenterologists (GIs). Hispanic and Asian backgrounds and smoking were linked to the type of adenoma and HP while SSA/P was not linked to race/ethnicity [19]. While colonoscopy is the best screening tool for CRC prevention, it has its own limitations due to its invasive nature which makes follow-up less desirable for surveillance purpose. Follow-up colonoscopy is necessary for $10-20 \%$ cases to prevent CRC within 6-60 months (interval colonoscopy) [20, 21]. Recent data has attributed SSA/Ps to both missed lesions and interval CRC development mostly in the right colon [11, 22, 23]. Additionally, the histopathological recognition of serrated polyps is still controversial for both experts and non-expert gastrointestinal pathologists [5, 20, 21, 23]. A recent study detected molecular markers specific to these type of lesions [24]. It identified previously undescribed, differential expression of miRNAs in SSA/Ps but not HPs, including miR135B, miR378A, miR548, miR9 and miR196B, suggesting that miRNAs, among other molecular markers, are good predictors of serrated neoplasia [24]. SSA/Ps are found in around $0.6 \%$ of patients undergoing routine screening colonoscopy, they account for $1-9 \%$ of all colonic polyps and $15-25 \%$ of all serrated lesions [9, 14, 25-27]. Histologically, they are characterized by architectural distortion, with basal crypt branching and dilatation (appear as flask or boot-shaped), serration, horizontal crypt orientation running to the muscularis mucosae, and mitoses in the upper levels of the crypts [8, 13, 28, 29]. African Americans bear a disproportionate share of the cancer burden,with the highest death rate and shortest survival of any racial or ethnic group for most cancers [2]. According to SEER 18 of National Cancer Institute, the number of deaths for AA from CRC was 52 per 100,000, compared to 40.6 for non-Hispanic Whites during 2009-2013 [30]. Despite these disparities, there are very few studies on clinicopathological and demographic features of serrated polyps in this high-risk population. The present study aims to assess SSA/Ps burden and associated features in an AA population.

\section{Methods}

We conducted a retrospective study of all colonoscopies performed at Howard University Hospital, Washington D.C. from January 1st, 2010 to December 31st, 2015. The data collection was anonymous and was approved by Howard University Institutional Review Board (IRB-MED-79). The corresponding endoscopy and pathology reports were reviewed $(n=12,085)$. Of these, $83 \%$ $(n=10,027)$ were from African American patients. We reviewed all pathology reports containing "Colorectal Polyp" in their diagnosis resulting in 4070 cases. Using the same pathology database, we searched for colonoscopies reporting "Serrated Polyps" in their diagnosis and we extracted data for 252 patients with such diagnosis. Out of these, 10 patients had multiple colonoscopies. The included SSA/P cases were originally read and diagnosed by board-certified pathologists at Howard University Hospital. For the purpose of our study, these cases were reviewed again by two gastrointestinal pathologists blinded to initial diagnoses of the polyps. Clinicopathological data including histopathological diagnosis, clinical and demographical data, number of polyps, location, size, and type of each polyp from the reports were abstracted. Weight, height, and BMI were added using electronic medical record database. Location of the polyps were categorized as right-sided and left-sided. Right-sided lesions were defined as those proximal to the splenic flexure, whereas left-sided were defined as lesions within and distal to the splenic flexure [31]. Different symptoms or indications for colonoscopy were placed into categories: screening, abdominal pain, gastrointestinal bleeding, change in bowel habits, anemia, pelvic mass, positive fecal occult blood test (FOBT), and weight loss. Subjects with family history of colon cancer, Familial Adenomatous Polyposis (FAP), Lynch Syndrome, and history of Inflammatory Bowel Disease (IBD) were excluded.

\section{Pathological classification of serrated polyps and associated subtypes}

Classification of polyps was extracted from pathology database (PowerPath) and reviewed by two expert GI pathologists. Polyp histology was categorized into six groups: Conventional adenomas (with or without high grade dysplasia), hyperplastic polyps, SSA/Ps (with or without high grade dysplasia), TSAs, mixed hyperplastic adenomatous polyp, and mixed adenomatous polyps with serrated architecture. SSA/Ps were diagnosed by architectural features based on four criteria: Crypt serration, crypt dilatation, crypts that run horizontal to the muscularis mucosae and crypts branching basally (appear mas flask or boot-shaped). Dysplasia was defined as either low or high grade. Advanced sessile serrated polyps were defined as polyps with cytological dysplasia and/or size $\geq 1 \mathrm{~cm}$. 


\section{Statistical analysis}

Distribution of continuous variables was presented with mean (SD) or median (interquartile range). We used t-test to compare the continuous variables between different groups and chi-square (or fisher exact) test for comparing the distribution of categorical variables.

\section{Results}

\section{Clinicopathological features and frequency of SSA/Ps}

The clinical and histopathological characteristics of the sessile serrated polyps are summarized in Table 1 . The total number of 252 African American patients diagnosed with SSA/Ps with or without dysplasia were included.

The frequency of polyps of any kind in this cohort was $41 \%(4070 / 10,027)$, and the prevalence of SSA/Ps with or without dysplasia was 6\% (252/4070). The median size for SSA/Ps regardless of location was $0.6 \mathrm{~cm}$. Age-wise, $71 \%$ of the patients were between 50 to 65 years and 120 patients $(48 \%)$ were obese with a $\mathrm{BMI}>$ 30. The most common reason for colonoscopy was screening (134, 53\%). For patients with clinical

Table 1 Demographic, clinical and pathology features of SSA/P patients

\begin{tabular}{ll}
\hline AA Patients with SSPS & $N=252$ \\
\hline Age mean, median (SD) (year) & $57.6,56.0(9.0)$ \\
Female & $136(54 \%)$ \\
BMI & \\
$<25$ & $35(14 \%)$ \\
$25-30$ & $97(38 \%)$ \\
$>30$ & $120(48 \%)$ \\
Reason for Colonoscopy & \\
Screening & $134(53 \%)$ \\
Diagnostic & $118(47 \%)$ \\
Number of All Polyps & \\
Specimen Number & 604 \\
Single & $82(33 \%)$ \\
Two & $77(30 \%)$ \\
$>2$ & $93(37 \%)$ \\
Number of SSA/P & \\
Specimen Number & 338 \\
Single & $190(75 \%)$ \\
Two & \\
$>2$ & $40(16 \%)$ \\
SSA/P Site & $22(9 \%)$ \\
Right & \\
Bilate & $37(15 \%)$ \\
Unspecified & $190(75 \%)$ \\
\hline & \\
\hline &
\end{tabular}

symptoms $(118,47 \%)$, change in bowel habits $(46 / 252$, $18 \%)$ and gastrointestinal bleeding (43/252, 17\%) were the more common symptoms.

The total number of all SSA/Ps in the 252 patients was 338 with an average number of $1.3 \mathrm{SSA} / \mathrm{Ps}$ per patient [190 patients $(75 \%)$ had one polyp, 40 patients (16\%) had two polyps, and 22 patients (9\%) had more than two polyps]. More than half of the patients (150, $60 \%$ had synchronous lesions with other types of histopathological features, with tubular adenoma being the most prevalent $(175 / 604,29 \%)$, followed by hyperplastic polyps $(83 / 604,14 \%)$, and mixed hyperplastic adenomatous polyps $(7 / 604,1 \%)$.

The total number of SSA/Ps with or without dysplasia were 338 polyps, in which $9 \%(n=29 / 338,29$ SSA/Ps-D in 23 patients) had some grade of cytological dysplasia. Also 83 (33\%) patients had advanced SSA/Ps (Table 2). Advanced SSA/Ps were defined as either large in size (> $1 \mathrm{~cm}$ ) and/or multiple synchronous lesions and/or cytological dysplasia. There was no significant difference regarding age, BMI, and gender when compared to non-advanced SSA/Ps patients. Positive FOBT was significantly higher in patients with advanced SSA/Ps $(P=0.028)$.

For location, $75 \%$ were in the left colon (Table 3). In our patient population, SSA/Ps were more likely to

Table 2 Clinicopathological features of the patients with Advanced versus Non-advanced SSA/Ps

\begin{tabular}{|c|c|c|c|}
\hline & $\begin{array}{l}\text { Non-advanced } \\
N=169\end{array}$ & $\begin{array}{l}\text { Advanced } \\
N=83\end{array}$ & $P$ value \\
\hline Age, median (IQR) & $56(51-63)$ & $57(51-62)$ & 0.9 \\
\hline Female & $94(56)$ & $42(51)$ & 0.5 \\
\hline BMI, median (IQR) & $29.3(26.5-34.0)$ & $29.8(26.5-35.2)$ & 0.7 \\
\hline Location, n (\%)* & & & 0.001 \\
\hline Left & $134(80)$ & $56(67)$ & \\
\hline Right & $26(15)$ & $11(13)$ & \\
\hline Bilateral & $8(5)$ & $16(19)$ & \\
\hline \multicolumn{4}{|l|}{ Symptoms, n (\%) } \\
\hline Abdominal pain & $19(11)$ & $12(14)$ & 0.5 \\
\hline Gl bleeding & $27(16)$ & $16(19)$ & 0.5 \\
\hline Screening & $106(63)$ & $45(54)$ & 0.2 \\
\hline FOBT+ & $3(2)$ & $6(7)$ & 0.028 \\
\hline Heartburn** & $15(9)$ & $9(11)$ & 0.6 \\
\hline Change in bowel habits & $32(19)$ & $14(17)$ & 0.7 \\
\hline Bloating** & $2(1)$ & 0 & 0.3 \\
\hline Anemia & $7(4)$ & $1(1)$ & 0.2 \\
\hline Pelvic mass & $1(0.6)$ & 0 & 0.5 \\
\hline Weight loss & $6(4)$ & $7(8)$ & 0.1 \\
\hline
\end{tabular}


Table 3 Characteristics of patients based on location of SSA/Ps

\begin{tabular}{llll} 
& Left & $\begin{array}{l}\text { Right } \\
N=37\end{array}$ & $P$ value \\
& $N=190$ & $56(52-62)$ & 0.4 \\
\hline Age, median (IQR) & $56(51-62)$ & $23(62)$ & 0.3 \\
Female, n (\%) & $102(54)$ & $28.3(25.8-31.6)$ & 0.17 \\
BMl, median (IQR) & $29.3(26.5-34.8)$ & & \\
Symptoms, n (\%) & & $6(16)$ & 0.4 \\
Abdominal pain & $22(12)$ & $10(27)$ & 0.053 \\
Gl bleeding & $27(14)$ & $20(54)$ & 0.3 \\
Screening & $119(63)$ & $1(3)$ & 0.8 \\
FOBT+ & $7(4)$ & $6(16)$ & 0.8 \\
Change in bowel habits & $34(18)$ & $1(3)$ & 0.8 \\
Anemia & $7(4)$ & 0 & 0.7 \\
Pelvic mass & $1(0.5)$ & $3(8)$ & 0.3 \\
Weight loss & $8(4)$ & & \\
\hline
\end{tabular}

be left-sided $(190,75 \%, P=0.06)$, with more frequency in rectum $(107 / 338,32 \%)$ and rectosigmoid (75/338, $22 \%)$. There was no significant difference between patients with right-sided polyps and left-sided polyps regarding age, gender, BMI, and clinical symptoms.

The median age for patients with SSA/Ps was 56 (IQR $=51-62)$ which was similar to patients with HPs (56, $p=0.5$; Table 4). On further comparison, the mean number of polyps detected for SSA/P patients was 1.3 , in contrast to mean number of polyps detected in hyperplastic patients $(1.2, P=0.009)$.

Table 4 Characteristics of SSA/P and HP patients

\begin{tabular}{llll}
\hline & SSA/P & HP & P value \\
& $N=252$ & $N=142$ & \\
\hline Age, median (IQR) & $56(51-62)$ & $56(52-62)$ & 0.5 \\
Female, n (\%) & $136(54)$ & $67(47)$ & 0.2 \\
Location, n (\%) & & & 0.06 \\
Left & $190(76)$ & $121(85)$ & \\
Right & $37(15)$ & $15(11)$ & \\
bilateral & $24(10)$ & $6(4)$ & \\
Number of polyp, mean (SD) & $1.3(0.7)$ & $1.2(0.5)$ & 0.009 \\
Clinical symptoms, n (\%) & & & \\
Abdominal pain & $31(12)$ & $26(18)$ & 0.10 \\
Gl bleeding & $43(17)$ & $24(17)$ & $>0.9$ \\
Screening & $151(60)$ & $85(60)$ & $>0.9$ \\
FOBT+ & $9(4)$ & $5(4)$ & $>0.9$ \\
Change in bowel habits & $46(18)$ & $21(15)$ & 0.7 \\
Anemia & $8(3)$ & $6(4)$ & 0.6 \\
Pelvic mass & $1(0.4)$ & 0 & 0.5 \\
Weight loss & $13(5)$ & $10(7)$ & 0.4 \\
Hemorrhoid & 0 & 0 & NA \\
\hline
\end{tabular}

*One patient had unknown location

\section{Discussion}

The aim of this retrospective study was to evaluate clinicopathological features of African American patients diagnosed with SSA/Ps. Considering that these lesions are a new diagnosis without uniform classification criteria among pathologists and as such their prevalence is controversial, underestimated, and varies between 0 to $1.2 \%$ in the literature [14, 27, 32-35]. The prevalence of SSA/Ps in our study was $2.5 \%$ (252/10,027 colonoscopies) which is higher than that published in other groups. The reason for this difference might be due to our study population and also the inclusion of colonoscopies including diagnostic procedures rather than just screening tests as in other studies. Even when considering screening colonoscopies only $(n=134)$, the SSA/Ps rate in our population is at the upper edge of $1.33 \%$, still higher than what is reported in other studies. Lower socioeconomic status is a risk factor for CRC as reported by DeNavas-Walt et al. African Americans in the U.S. have the lowest income [36]. Obesity rate in our patients was $48 \%$. Obesity has been cited as a risk factor for serrated polyps mostly in the left side of the colon $[37,38]$. It is worth noting that most SSA/Ps in our study were distal which give some credibility to the SSA/Ps-obesity link that are primarily in the left colon as in AA population. Other cited risk factors for serrated polyps are dietary habits and smoking which we did not collect for our study.

Colorectal cancer is highest among African Americans [1], and the prevalence of polyps in general is higher in African Americans who are usually diagnosed at advanced stages [39, 40]. However, there are no studies showing higher prevalence of sessile serrated polyps in this population. Wallace et al. conducted a research on the association of race, age and developing colorectal polyps in 2014, demonstrating that African Americans have a lower risk of developing serrated polyps, but they did not subcategorize the serrated polyps into SSA/Ps, HPs, and TSAs [37]. In another study, SSA/Ps prevalence was reported as lower in low-income AAs compared to whites (2 vs. $8 \%$ ) [41]. In a prospective study of 190 Caucasian patients undergoing colonoscopy by a single operator, during a five month period at the Royal Brisbane and Women's Hospital in Australia, Spring et al. reported that the prevalence of SSPs in their population was $13.8 \%$ of all colonoscopies and $9 \%$ of all detected polyps [42]. Kumbhari et al. in Australia, compared SSA/Ps prevalence between Caucasians and Chinese, and reported higher prevalence of SSA/Ps in Caucasians (7\% vs. 2\%) [43]. These two studies demonstrate a strikingly higher prevalence of SSA/Ps in the Australian Caucasian population, showing non-homogenous reports on SSA/Ps' prevalence around the world. This emphasizes the need for 
more prospective research on this matter. In a more recent study in 759 serrated adenomas from Irish patients, McCarthy et al. reported that after a review of the cases 100 cases were reclassified, with the majority being changed from SSA/P to hyperplastic polyps, further stressing the need for meticulous review before stating final diagnosis, and while the majority of SSA/Ps were in the right colon $(86.7 \%)$, most TSAs were in the left colon (85.7\%) [44].

In our study, SSA/Ps account for $6 \%$ of all patients with detected polyps $(n=4070)$ which is in agreement with other studies demonstrating a rate of 1 to $9 \%$ [8, $13,23,26,27]$. Overall the average age in our population was 57.6 ( \pm 8.9 years), and $12 \%$ of them were < 50 years old showing the advantage of starting screening colonoscopy at a younger age of 45 , if not earlier as we previously recommended for African Americans $[45,46]$. In contrast, the mean age at diagnosis for hyperplastic polyps was $62( \pm 11$ years $)$ in previous reports [47]. SSA/Ps frequency was reported as very close in both sexes with a slight predominance in females, which is in agreement with our results (54\% in females). The total number of SSA/Ps in our study was 338 in 252 patients, out of which 9\% $(n=29 / 338)$ had some grade of cytological dysplasia. The average number of SSA/Ps per patient was 1.3 , with $75 \%$ of patients having one SSA/P, 16\% with two SSA/Ps, and $9 \%$ with more than two SSA/Ps with a range of one to four. In a study by Gurudu et al., synchronous polyps along with SSA/Ps were found to be present in $51 \%$ of the patients, with $49 \%$ being tubular adenoma, $10 \%$ tubulovillous adenoma and $40 \%$ hyperplastic polyps [48]. In our study, more than half of the patients $(150,60 \%)$ had synchronous lesions with other types of histopathological features, with tubular adenoma being the most prevalent (29\%, 175/604), followed by hyperplastic polyps $(14 \%, 83 / 604)$, and mixed hyperplastic adenomatous polyps (1\%, 8/604). In general, the average number of all polyps per patient was 2.4 (604 polyps in 252 patients with a range of 1 to 9 ). The range of mean polyps per patient is various in different studies and is around 0.2 to 3.2 and is highly affected by operators and endoscopy performance $[17,42,49]$. Since SSA/Ps are a new diagnosis, there is no credible data on the mean number of SSA/Ps per patient and it appears to be significantly underdiagnosed in clinical practice. Its diagnosis is highly variable between practitioner endoscopists and pathologists [11, 32, 33, 50-52]. The flat appearance and mucinous feature of these polyps make them hard to detect at endoscopy and their characteristic histologic features and location in the crypt base rather than the mucosal surface make them difficult to dissociate from other serrated lesions
[5, 27, 53, 54]. Lack of uniform pathologic criteria amongst pathologists may account for the misdiagnosis of serrated polyps $[5,20,21,23]$. The other important reason for underdiagnosis is bowel preparation before endoscopy and the quality of endoscopy [11, 32, 33, 50-52]. It has been suggested that the inability to detect and resect SSA/Ps might be one cause of the lower detection of these lesions leading to the development of interval cancers [20, 54]. There is a hypothesis that patients with SSA/Ps, have a higher chance of developing synchronous serrated polyps, metachronous adenoma and CRC [32, $38,55]$. But it is unclear, whether this is due to genetic alterations in these patients making them more susceptible to develop neoplastic polyps or due to some genetic/epigenetic alterations specific to these lesions. Burnett-Hartman et al. reported that age, obesity, NSAID use, and family history of colorectal cancer have stronger association with synchronous adenoma and serrated polyps than those with only 1 type of polyp [38]. Since these are known risk factors for colorectal cancer, more vigilance to patients with $\mathrm{SSA} / \mathrm{Ps}$ is recommended.

Some SSA/Ps may develop different grades of cytological dysplasia, which have greater chances of becoming cancerous. In recent studies, the range of SSA/Ps with dysplasia was reported to be around 0.3 to $25 \%$ [14, $27,32,56,57]$. The rate of dysplasia in our AA population was $8.57 \%$ when considering total SSAPs (29/338) and $9.1 \%$ when considering patients with dysplasia (23/ 252). Average size for SSA/Ps is typically more than 5 $\mathrm{mm}[28,34,56-59]$. There are some suggestions on larger size SSA/Ps with increasing age or developing dysplasia [56], but in our data there is no difference in the mean size of SSA/Ps in all locations and in all age ranges (6 mm).

The most common reason for colonoscopy in our study was screening $(134,53 \%)$. For patients with clinical symptoms $(118,47 \%)$ undergoing diagnostic colonoscopy, changes in bowel habits $(46 / 252,18 \%)$ and gastrointestinal bleeding $(43 / 252,17 \%)$ were the most common symptoms. Some studies have shown that asymptomatic AAs have a greater risk of developing polyps and CRC compared to whites $[40,46,60]$. In recent studies, clinical symptoms associating with SSA/Ps were: anemia, blood per rectum, weight loss, and abdominal discomfort [26, 34, 35]. However, the most common reason for colonoscopy in these patients was screening in most studies which is in agreement with our results [11, 35, 46, 59]. Clinical symptoms associated with colorectal adenomas are blood per rectum and anemia due to polyp bleeding, and symptoms like diarrhea, constipation, and abdominal pain due to polyps' direct compression to structures around it. But sessile 
serrated polyps are flat in shape, hence they may not present with such clinical symptoms. In our patient population, SSA/Ps were more likely to be distal (190, $75 \%)$, with more prevalence in the rectum (107/338, $32 \%)$ and rectosigmoid $(75 / 338,22 \%)$. Patients with right-sided polyps were significantly older (mean age of 60 years in comparison to 56 years, $P<0.05)$. As such, the prevalence of left-sided SSA/Ps in younger patients might point to a new etiology of CRC in AAs and might be a participating factor in the overall CRC disparity in this population.

The limitation of this study was that it was a retrospective study; hence, we could not collect information on bowel preparation quality, diet and smoking habits that are factors in the etiology and detection of such flat lesions.

Due to either small sample size studies [17, 61], or non-categorization of SSA/Ps with the current definition [26], SSA/Ps remain underdiagnosed. The flat appearance of these polyps or endoscopist experience might not be the reason for this discrepancy, since they were predominantly detected in the left side of the colon in previous studies. There is a hypothesis that suggests that some of the SSA/Ps arise from hyperplastic polyps $[5,62,63]$. There might be some interobserver error misdiagnosing some of the SSA/Ps as HPs, or vice-versa. However, a better understanding of the molecular features of serrated lesions will facilitate a more objective approach for discriminating these lesions, even though they seem to share many features. $[10,11,23,64,65]$. Although there are some recent findings $[18,23]$ on gene alteration to differentiate these two types of polyps $[9,11,12,28,62,66]$, further understanding of the serrated lesions at the genetic level is needed in addition to a prospective study in the African American population.

\section{Conclusion}

The prevalence of SSPs accounts for 6\% of all polyps in AA patients and was diagnosed in $2.5 \%$ of all colonoscopies $(n=252 / 10,027)$, which is higher than Caucasians in the US. SSPs were predominantly located in the left side, as compared to published literature showing the predominance in the right side of the colon. Screening of CRC will have the chance to detect high risk SSA/P in this population.

\section{Acknowledgements}

Not applicable.

\section{Funding}

This project was supported (in part) by the National Institute on Minority Health and Health Disparities of the National Institutes of Health under Award Number G12MD007597.

\section{Availability of data and materials}

The datasets used and analysed during the current study are available from the corresponding author on reasonable request.

\section{Authors' contributions}

Conceived and designed experiments: HA, MN; Performed experiments: HA, $\mathrm{HB}, \mathrm{EL}, \mathrm{BS}$; Analyzed data: TT, SA, SS, HA, HB, AOL ; Contributed reagents/ materials/analysis tools: AA, AS, NA; Wrote and edited manuscript: HA, MN, $H B$; Provided statistical analysis: MN. All authors read approved the final manuscript.

\section{Ethics approval and consent to participate}

The study was approved by the Institutional Review Board (IRB) of Howard University. Written consent was waived by the institutional review board because of the retrospective study design (IRB approval reference number 06-MED-39).

\section{Consent for publication}

Not applicable.

\section{Competing interests}

The authors declare that they have no competing interests.

\section{Publisher's note}

Springer Nature remains neutral with regard to jurisdictional claims in published maps and institutional affiliations.

\section{Author details}

${ }^{1}$ University of Pittsburg, Medical center, Pittsburg, PA, USA. ${ }^{2}$ Department of Medicine, College of Medicine, Washington, DC, USA. ${ }^{3}$ Pathology

Department, Cancer Center, College of Medicine, Washington, DC, USA ${ }^{4}$ Cancer Research Center and Department of Medicine, Howard University College of Medicine, 2041 Georgia Avenue, Washington, D.C, N.W. 20060,

USA. ${ }^{5}$ Division of Pulmonary, Allergy and Critical Care Medicine, Department of Medicine, University of Pittsburgh, Pittsburgh, USA.

Received: 24 November 2018 Accepted: 16 May 2019

Published online: 24 May 2019

\section{References}

1. Siegel RL, Miller KD, Jemal A. Cancer statistics, 2016. CA Cancer J Clin. 2016; 66(1):7-30.

2. DeSantis CE, Siegel RL, Sauer AG, Miller KD, Fedewa SA, Alcaraz Kl, Jemal A. Cancer statistics for African Americans, 2016: Progress and opportunities in reducing racial disparities. CA Cancer J Clin. 2016.

3. Imperiale TF, Abhyankar PR, Stump TE, Emmett TW. Prevalence of advanced, precancerous colorectal neoplasms in black and white populations: a systematic review and meta-analysis. Gastroenterology. 2018;155(6):17761786 e1771.

4. Saito S, Tajiri H, Ikegami M. Serrated polyps of the colon and rectum: endoscopic features including image enhanced endoscopy. World J Gastrointest Endosc. 2015;7(9):860-71.

5. Rex DK, Ahnen DJ, Baron JA, Batts KP, Burke CA, Burt RW, Goldblum JR, Guillem JG, Kahi CJ, Kalady MF, et al. Serrated lesions of the colorectum: review and recommendations from an expert panel. Am J Gastroenterol. 2012;107(9):1315-29; quiz 1314, 1330.

6. Urbanski SJ, Kossakowska AE, Marcon N, Bruce WR. Mixed hyperplastic adenomatous polyps--an underdiagnosed entity. Report of a case of adenocarcinoma arising within a mixed hyperplastic adenomatous polyp. Am J Surg Pathol. 1984;8(7):551-6.

7. Longacre TA, Fenoglio-Preiser CM. Mixed hyperplastic adenomatous polyps/ serrated adenomas. A distinct form of colorectal neoplasia. Am J Surg Pathol. 1990;14(6):524-37.

8. BBosman FT, Carneiro F, Hruban RH, Theise ND. WHO classification of Tumours of the digestive system, fourth edition, vol. 3; 2010.

9. Kanth P, Bronner MP, Boucher KM, Burt R, Neklason DW, Hagedorn $\mathrm{CH}$, Delker DA. Gene signature in sessile serrated polyps identifies Colon Cancer subtype. Cancer Prev Res (Phila). 2016.

10. Sweetser S, Smyrk TC, Sinicrope FA. Serrated colon polyps as precursors to colorectal cancer. Clinical gastroenterology and hepatology : the official 
clinical practice journal of the American Gastroenterological Association. 2013;11(7):760-7 quiz e754-765.

11. Sweetser S, Jones A, Smyrk TC, Sinicrope FA. Sessile serrated polyps are precursors of Colon carcinomas with deficient DNA mismatch repair. Clinical gastroenterology and hepatology : the official clinical practice journal of the American Gastroenterological Association. 2016.

12. Delker DA, McGettigan BM, Kanth P, Pop S, Neklason DW, Bronner MP, Burt RW, Hagedorn CH. RNA sequencing of sessile serrated colon polyps identifies differentially expressed genes and immunohistochemical markers. PLoS One. 2014;9(2):e88367.

13. Torlakovic E, Skovlund E, Snover DC, Torlakovic G, Nesland JM. Morphologic reappraisal of serrated colorectal polyps. Am J Surg Pathol. 2003;27(1):65-81.

14. Lash RH, Genta RM, Schuler CM. Sessile serrated adenomas: prevalence of dysplasia and carcinoma in 2139 patients. J Clin Pathol. 2010;63(8):681-6.

15. Limketkai BN, Lam-Himlin D, Arnold CA, Arnold MA. The cutting edge of serrated polyps: a practical guide to approaching and managing serrated colon polyps. Gastrointest Endosc. 2013;77(3):360-75.

16. Makinen MJ, George SM, Jernvall P, Makela J, Vihko P, Karttunen TJ. Colorectal carcinoma associated with serrated adenoma--prevalence, histological features, and prognosis. J Pathol. 2001;193(3):286-94.

17. Higuchi T, Sugihara K, Jass JR. Demographic and pathological characteristics of serrated polyps of colorectum. Histopathology. 2005;47(1):32-40.

18. Kawasaki K, Kurahara K, Yanai S, Oshiro Y, Yao T, Kobayashi H, Nakamura S, Fuchigami T, Sugai T, Matsumoto T. Colonoscopic features and malignant potential of sessile serrated adenomas: comparison with other serrated lesions and conventional adenomas. Color Dis. 2016.

19. Li D, Woolfrey J, Jiang SF, Jensen CD, Zhao WK, Kakar S, Santamaria M, Rumore G, Armstrong MA, Postlethwaite $D$, et al. Diagnosis and predictors of sessile serrated adenoma after educational training in a large, community-based, integrated healthcare setting. Gastrointest Endosc. 2018; 87(3):755-765 e751.

20. Clark BT, Laine L. High-quality bowel preparation is required for detection of sessile serrated polyps. Clinical gastroenterology and hepatology : the official clinical practice journal of the American Gastroenterological Association. 2016.

21. JE IJ, de Wit K, van der Vlugt M, Bastiaansen BA, Fockens P, Dekker E. Prevalence, distribution and risk of sessile serrated adenomas/polyps at a center with a high adenoma detection rate and experienced pathologists. Endoscopy. 2016.

22. Samadder NJ, Curtin K, Tuohy TM, Pappas L, Boucher K, Provenzale D, Rowe KG, Mineau GP, Smith K, Pimentel R, et al. Characteristics of missed or interval colorectal cancer and patient survival: a population-based study. Gastroenterology. 2014;146(4):950-60.

23. Renaud F, Mariette C, Vincent A, Wacrenier A, Maunoury V, Leclerc J, Coppin L, Crepin M, Van Seuningen I, Leteurtre E, et al. The serrated neoplasia pathway of colorectal tumors: identification of MUC5AC hypomethylation as an early marker of polyps with malignant potential. Int J Cancer. 2016. 138(6):1472-81.

24. Kanth P, Hazel MW, Boucher KM, Yang Z, Wang L, Bronner MP, Boylan K, Burt RW, Westover M, Neklason DW, et al. Small RNA sequencing of sessile serrated polyps identifies microRNA profile associated with colon cancer. Genes, chromosomes \& cancer. 2018.

25. Limketkai BN, Lam-Himlin D, Arnold MA, Arnold CA. The cutting edge of serrated polyps: a practical guide to approaching and managing serrated colon polyps. Gastrointest Endosc. 2013;77(3):360-75.

26. Chandra A, Sheikh AA, Cerar A, Talbot IC. Clinico-pathological aspects of colorectal serrated adenomas. World J Gastroenterol. 2006;12(17):2770-2.

27. Hetzel JT, Huang CS, Coukos JA, Omstead K, Cerda SR, Yang S, O'Brien MJ, Farraye FA. Variation in the detection of serrated polyps in an average risk colorectal cancer screening cohort. Am J Gastroenterol. 2010;105(12): 2656-64.

28. Aust DE, Baretton GB. Serrated polyps of the colon and rectum (hyperplastic polyps, sessile serrated adenomas, traditional serrated adenomas, and mixed polyps)-proposal for diagnostic criteria. Virchows Arch. 2010;457(3):291-7.

29. Muto Y, Maeda T, Suzuki K, Kato T, Watanabe F, Kamiyama H, Saito M, Koizumi K, Miyaki Y, Konishi F, et al. DNA methylation alterations of AXIN2 in serrated adenomas and colon carcinomas with microsatellite instability. BMC Cancer. 2014:14:466.

30. Surveillance, Epidemiology, and End Results (SEER) Program. SEER Cancer Statistics Review, 1975-2013, National Cancer Institute. [http://seer.cancer. gov/csr/].
31. Wang F, Bai L, Liu TS, Yu YY, He MM, Liu KY, Luo HY, Zhang DS, Jin Y, Wang $\mathrm{FH}$, et al. Right-sided colon cancer and left-sided colorectal cancers respond differently to cetuximab. Chinese journal of cancer. 2015;34(9):384-93.

32. Pai RK, Hart J, Noffsinger AE. Sessile serrated adenomas strongly predispose to synchronous serrated polyps in non-syndromic patients. Histopathology. 2010;56(5):581-8.

33. Kahi CJ, Hewett DG, Norton DL, Eckert GJ, Rex DK. Prevalence and variable detection of proximal colon serrated polyps during screening colonoscopy. Clinical gastroenterology and hepatology: the official clinical practice. journal of the American Gastroenterological Association. 2011;9(1):42-6.

34. Bariol C, Hawkins NJ, Turner JJ, Meagher AP, Williams DB, Ward RL. Histopathological and clinical evaluation of serrated adenomas of the colon and rectum. Modern pathology : an official journal of the United States and Canadian Academy of Pathology, Inc. 2003;16(5):417-23.

35. Cao HL, Chen X, Du SC, Song WJ, Wang WQ, Xu MQ, Wang SN, Piao MY, Cao XC, Wang BM. Detection rate, distribution, clinical and pathological features of colorectal serrated polyps. Chin Med J. 2016;129(20):2427-33.

36. DeNavas-Walt C, Proctor BD, Smith JC, Census Bureau US. Income and poverty in the United States : 2013. Washington, D.C.: United States Census Bureau; 2014.

37. Wallace K, Grau MV, Ahnen D, Snover DC, Robertson DJ, Mahnke D, Gui J, Barry EL, Summers RW, McKeown-Eyssen G, et al. The association of lifestyle and dietary factors with the risk for serrated polyps of the colorectum. Cancer epidemiology, biomarkers \& prevention : a publication of the American Association for Cancer Research, cosponsored by the American Society of Preventive. Oncology. 2009;18(8):2310-7.

38. Burnett-Hartman AN, Passarelli MN, Adams SV, Upton MP, Zhu LC, Potter JD, Newcomb PA. Differences in epidemiologic risk factors for colorectal adenomas and serrated polyps by lesion severity and anatomical site. Am J Epidemiol. 2013;177(7):625-37.

39. Lieberman DA, Williams JL, Holub JL, Morris CD, Logan JR, Eisen GM, Carney P. Race, ethnicity, and sex affect risk for polyps $>9 \mathrm{~mm}$ in average-risk individuals. Gastroenterology. 2014;147(2):351-8 quiz e314-355.

40. Thornton JG, Morris AM, Thornton JD, Flowers CR, McCashland TM. Racial variation in colorectal polyp and tumor location. J Natl Med Assoc. 2007; 99(7):723-8.

41. Wallace K, Brandt HM, Bearden JD, Blankenship BF, Caldwell R, Dunn J, Hegedus P, Hoffman BJ, Marsh CH, Marsh WH, et al. Race and prevalence of large bowel polyps among the low-income and uninsured in South Carolina. Dig Dis Sci. 2016;61(1):265-72.

42. Spring K, Zhao ZZ, Karamatic R, Walsh MD, Whitehall VL, Pike T, Simms LA, Young J, James M, Montgomery GW, et al. High prevalence of sessile serrated adenomas with BRAF mutations: a prospective study of patients undergoing colonoscopy. Gastroenterology. 2006;131(5):1400-7.

43. Kumbhari V, Behary J, Hui JM. Prevalence of adenomas and sessile serrated adenomas in Chinese compared with Caucasians. J Gastroenterol Hepatol. 2013;28(4):608-12

44. McCarthy AJ, O'Reilly SM, Shanley J, Geraghty R, Ryan EJ, Cullen G, Sheahan K. Colorectal serrated neoplasia: an institutional 12-year review highlights the impact of a screening Programme. Gastroenterol Res Pract. 2019;2019: 1592306.

45. Rex DK, Johnson DA, Anderson JC, Schoenfeld PS, Burke CA, Inadomi JM: American College of Gastroenterology guidelines for colorectal Cancer screening 2008 .Am J Gastroenterol 2009, 104(6):1612-1612.

46. Lieberman DA, Rex DK, Winawer SJ, Giardiello FM, Johnson DA, Levin TR. Guidelines for colonoscopy surveillance after screening and polypectomy: a consensus update by the US multi-society task force on colorectal Cancer. Gastroenterology. 2012;143(3):844-57.

47. Kalady MF, Jarrar A, Leach B, LaGuardia L, O'Malley M, Eng C, Church JM. Defining phenotypes and cancer risk in hyperplastic polyposis syndrome. Dis Colon Rectum. 2011;54(2):164-70.

48. Gurudu SR, Heigh Rl, De Petris G, Heigh EG, Leighton JA, Pasha SF, Malagon IB, Das A. Sessile serrated adenomas: demographic, endoscopic and pathological characteristics. World J Gastroenterol. 2010;16(27):3402-5.

49. Denis B, Sauleau EA, Gendre I, Exbrayat C, Piette C, Dancourt V, Foll Y, Ait Hadad H, Bailly L, Perrin P: The mean number of adenomas per procedure should become the gold standard to measure the neoplasia yield of colonoscopy: a population-based cohort study. Gastroenterology and the Italian Digestive and liver disease : official journal of the Italian Society of Association for the Study of the Liver 2014, 46(2):176-181. 
50. Khalid O, Radaideh S, Cummings OW, O'Brien MJ, Goldblum JR, Rex DK. Reinterpretation of histology of proximal colon polyps called hyperplastic in 2001. World J Gastroenterol. 2009;15(30):3767-70.

51. de Wijkerslooth TR, Stoop EM, Bossuyt PM, Tytgat KM, Dees J, MathusVliegen EM, Kuipers EJ, Fockens P, van Leerdam ME, Dekker E. Differences in proximal serrated polyp detection among endoscopists are associated with variability in withdrawal time. Gastrointest Endosc. 2013;77(4):617-23.

52. Farris AB, Misdraji J, Srivastava A, Muzikansky A, Deshpande V, Lauwers GY, Mino-Kenudson M. Sessile serrated adenoma: challenging discrimination from other serrated colonic polyps. Am J Surg Pathol. 2008;32(1):30-5.

53. Okamoto K, Kitamura S, Kimura T, Nakagawa T, Sogabe M, Miyamoto H, Muguruma N, Takayama T. Clinicopathological characteristics of serrated polyps as precursors to colorectal Cancer: current status and management. J Gastroenterol Hepatol. 2016.

54. Liang J, Kalady MF, Appau K, Church J. Serrated polyp detection rate during screening colonoscopy. Color Dis. 2012;14(11):1323-7.

55. Kellokumpu I, Kyllonen L. Multiple adenomas and synchronous hyperplastic polyps as predictors of metachronous colorectal adenomas. Ann Chir Gynaecol. 1991;80(1):30-5.

56. Murakami T, Sakamoto N, Ritsuno H, Shibuya T, Osada T, Mitomi H, Yao T, Watanabe S. Distinct endoscopic characteristics of sessile serrated adenoma/polyp with and without dysplasia/carcinoma. Gastrointest Endosc. 2017;85(3):590-600.

57. Chino A, Yamamoto N, Kato Y, Morishige K, Ishikawa H, Kishihara T, Fujisaki J, Ishikawa Y, Tamegai Y, Igarashi M. The frequency of early colorectal cancer derived from sessile serrated adenoma/polyps among 1858 serrated polyps from a single institution. Int J Color Dis. 2016;31(2):343-9.

58. Groff RJ, Nash R, Ahnen DJ. Significance of serrated polyps of the colon. Current gastroenterology reports. 2008;10(5):490-8.

59. Abdeljawad K, Vemulapalli KC, Kahi CJ, Cummings OW, Snover DC, Rex DK Sessile serrated polyp prevalence determined by a colonoscopist with a high lesion detection rate and an experienced pathologist. Gastrointest Endosc. 2015:81(3):517-24.

60. Winawer S, Fletcher R, Rex D, Bond J, Burt R, Ferrucci J, Ganiats T, Levin T, Woolf S, Johnson D, et al. Colorectal cancer screening and surveillance: clinical guidelines and rationale - update based on new evidence. Gastroenterology. 2003:124(2):544-60

61. Mirzaie AZ, Khakpour H, Mireskandari M, Shayanfar N, Fatahi L. Investigating the frequency of serrated polyps/adenomas and their subtypes in colonic polyp samples. Med Arch. 2016;70(3):198-202.

62. Maeda T, Suzuki K, Togashi K, Nokubi M, Saito M, Tsujinaka S, Kamiyama H Konishi F. Sessile serrated adenoma shares similar genetic and epigenetic features with microsatellite unstable colon cancer in a location-dependent manner. Exp Ther Med. 2011;2(4):695-700.

63. Bordacahar B, Barret M, Terris B, Dhooge M, Dreanic J, Prat F, Coriat R, Chaussade $\mathrm{S}$. Sessile serrated adenoma: from identification to resection. Digest Liver Dis. 2015;47(2):95-102.

64. Yamane L, Scapulatempo-Neto C, Reis RM, Guimaraes DP. Serrated pathway in colorectal carcinogenesis. World J Gastroenterol. 2014;20(10):2634-40.

65. Sakai E, Fukuyo M, Ohata K, Matsusaka K, Doi N, Mano Y, Takane K, Abe H, Yagi K, Matsuhashi N, et al. Genetic and epigenetic aberrations occurring in colorectal tumors associated with serrated pathway. Int J Cancer. 2016; 138(7):1634-44.

66. Caruso M, Fung KYC, Moore J, Brierley GV, Cosgrove LJ, Thomas M, Cheetham G, Brook E, Fraser LM, Tin T, et al. Claudin-1 expression is elevated in colorectal Cancer precursor lesions harboring the BRAF V600E mutation. Transl Oncol. 2014;7(4):456-63.

Ready to submit your research? Choose BMC and benefit from:

- fast, convenient online submission

- thorough peer review by experienced researchers in your field

- rapid publication on acceptance

- support for research data, including large and complex data types

- gold Open Access which fosters wider collaboration and increased citations

- maximum visibility for your research: over $100 \mathrm{M}$ website views per year

At BMC, research is always in progress.

Learn more biomedcentral.com/submissions 